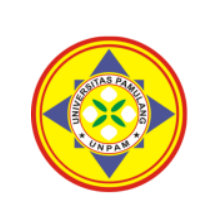

\title{
PENGARUH KECERDASAN EMOSIONAL DAN BEBAN KERJA TERHADAP KINERJA KARYAWAN PADA PT SONY INDONESIA DI JAKARTA PUSAT
}

\author{
${ }^{1 *}$ Muhammad Gandung, 2Suwanto \\ Universitas Pamulang, Tangerang Selatan, Banten, Indonesia \\ *dosen02020@unpam.ac.id
}

\begin{abstract}
Abstrak
Penelitian ini bertujuan untuk mengetahui pengaruh kecerdasan emosional dan beban kerja terhadap kinerja karyawan baik secara parsial maupun simultan pada PT. Sony Indonesia di Jakarta Pusat. Metode penelitian yang digunakan dalam penelitian ini adalah metode kuantitatif. Adapun teknik pengumpulan data dalam penelitian ini dengan menyebarkan kuesioner kepada beberapa karyawan sebagai samplenya, dan teknik analisis data yang digunakan pada penelitian ini yaitu uji validitas, uji reliabilitas, uji asumsi klasik, analisis deskriptif, uji regresi linear sederhana, uji regresi linear berganda, uji koefisien korelasi, uji koefisien determinasi, Uji hipotesis parsial $(\mathrm{t})$ dan $\operatorname{simultan}(\mathrm{f})$. Teknik sampling yang digunakan adalah teknik sampling slovin yaitu sebanyak 62 responden. Hasil penelitian menunjukan bahwa kecerdasan emosional dan beban kerja berpengaruh terhadap kinerja karyawan dengan persamaan regresi linear berganda $\mathrm{Y}=8,941+0,124 \mathrm{X}_{1}+0,836 \mathrm{X}_{2}$, dengan nilai koefisien determinasi $41,5 \%$ sedangkan sisanya $58,5 \%$ adalah variabel lain yang tidak diteliti, artinya meskipun tanpa ada pengaruh variabel kecerdasan emosiona (X1) dan beban kerja (X2), maka karyawan tetap memiliki tingkat kinerja sebesar 8,941. Hasil uji hipotesis secara parsial kecerdasan emosional tidak berpengaruh terhadap kinerja karyawan dengan hasil uji $t$ hitung $<\mathrm{t}$ tabel atau 1,152 $<2,00100$ maka $\mathrm{H}_{01}$ diterima dan $\mathrm{H}_{\mathrm{a} 1}$ ditolak. Secara parsial beban kerja berpengaruh terhadap kinerja karyawan dengan hasil uji thitung $>\mathrm{t}$ tabel atau 6,447 > 2,00100 maka $\mathrm{H}_{02}$ ditolak dan $\mathrm{H}_{\mathrm{a} 2}$ diterima. Hasil uji hipotesis secara simultan nilai Fhitung $>$ Ftabel atau 20,942 > 3,15, maka $\mathrm{H}_{03}$ ditolak dan $\mathrm{H}_{\mathrm{a} 3}$ diterima. Dapat disimpulkan bahwa hasil penelitian menunjukkan kecerdasan emosional dan beban kerja berpengaruh terhadap kinerja karyawan pada PT.Sony Indonesia di Jakarta Pusat.
\end{abstract}

Kata Kunci: Kecerdasan Emosional Dan Beban Kerja Terhadap Kinerja Karyawan

\section{Abstract}

This study aims to determine the effect of emotional intelligence and workload on employee performance either partially or simultaneously at PT. Sony Indonesia in Central Jakarta. The research method used in this study is a quantitative method. The data collection techniques in this study were by distributing questionnaires to several employees as samples, and the data analysis techniques used in this study were validity test, reliability test, classical assumption test, descriptive analysis, simple linear regression test, multiple linear regression test, test correlation coefficient, coefficient of determination test, partial hypothesis test $(t)$ and simultaneous $(f)$. The sampling technique used is the slovin sampling technique as many as 62 respondents. The results showed that emotional intelligence and workload had an effect on employee performance with the multiple linear regression equation $Y=8.941+0.124 X 1+0.836 X 2$, with a coefficient of determination of $41.5 \%$ while the remaining $58.5 \%$ were other variables not examined, meaning that even without the influence of emotional intelligence (X1) and workload (X2) variables, employees still have a performance level of 8.941. The results of the partial hypothesis test of emotional intelligence have no effect on employee performance with the results of the $t$-test $<t$ table or 1.152 $<2.00100$ then H01 is accepted and Ha1 is rejected. Partially the workload affects employee performance with the results of the $t$-test $>t$ table or $6.447>2.00100$, so $\mathrm{H} 02$ is rejected and $\mathrm{Ha} 2$ is accepted. The results of simultaneous hypothesis testing are Fcount > Ftable or $20.942>3.15$, then HO3 is rejected and Ha3 is accepted. It can be concluded that the results of the study indicate that emotional intelligence and workload affect employee performance at PT. Sony Indonesia in Central Jakarta.

Keywords: Emotional Intelligence And Workload On Employee Performance 


\section{PENDAHULUAN}

PT. Sony Indonesia merupakan salah satu perusahaan yang bergerak di bidang elektronik yang menyediakan berbagai macam perlengkapan elektonik, PT. Sony Indonesia adalah organisasi yang mempunyai berbagai macam tujuan. Dalam pencapaian tujuan tersebut diperlukan pengelolaan faktor-faktor produksi yang terdiri dari sumber daya alam, sumber daya manusia, modal, bahan baku, mesin, dan teknologi.

Salah satu faktor yang cukup berpengaruh terhadap kinerja karyawan dari sumber daya manusia yang dimiliki oleh PT. Sony Indonesia di Jakarta Pusat adalah faktor kecerdasan emosional dan beban kerja. Kecerdasan emosional adalah kemampuan seseorang untuk menerima, menilai, mengelola, serta mengontrol emosi dirinya dan orang lain di sekitarnya. Dalam hal ini, emosi mengacu pada perasaan terhadap informasi akan suatu hubungan. Beban kerja adalah sesuatu yang muncul yang dikarenakan jumlah kegiatan atau tugas-tugas yang harus diselesaikan oleh karyawan secara sistematis dengan menggunakan keterampilan yang harus diselesaikan berdasarkan waktu.

Menurut Siswanto (2017:38) menyatakan "beban kerja adalah sejumlah kegiatan yang harus diselesaikan oleh suatu unit organisasi atau pemegang jabatan secara sistematis dengan menggunakan teknis analisis jabatan, teknik analisis beban kerja, atau teknik manajemen lainnya dalam jangka waktu tertentu untuk mendapatkan informasi tentang efisiensi dan efektivitas kerja suatu unit organisasi."

Untuk melihat bagaimana kondisi sebenarnya mengenai kecerdasan emosional dan beban kerja karyawan pada PT. Sony Indonesia di Jakarta Pusat dilakukan observasi langsung ke lapangan terkait dengan kecerdasan emosional. Indikator kecerdasan emosional yang penulis gunakan dalam penelitian ini adalah indikator kecerdasan emosional menurut Goleman (2016), diantaranya adalah kesadaran diri karyawan terhadap tanggung jawab dalam pekerjaannya, kemampuan mengatur diri karyawan terhadap pekerjaannya, memotivasi diri sendiri dan orang lain atau rekan kerjanya, rasa empati karyawan terhadap rekan kerjanya di dalam lingkungan kerja, dan cara memelihara hubungan sosial sesama karyawan.

\section{TINJAUAN PUSTAKA}

\section{A. Kecerdasan Emosional}

Menurut

Mangkunegara

(2017:164), “kecerdasan emosional adalah kemampuan untuk memahami diri dan orang lain secara benar, memiliki jati diri, kepribadian dewasa mental. Tidak iri hati, tidak benci, tidak sakit hati, tidak dendam, tidak memiliki perasaan bersalah yang berlebihan, tidak cemas, tidak mudah marah dan tidak mudah frustasi".

Konsep kecerdasan emosi berarti memilki kesadaran diri yang memungkinkan untuk mengenali perasaan-perasaan dan mengelola emosi diri sendiri, dan itu melibatkan motivasi diri dan mampu untuk fokus pada sebuah tujuan dari pada menuntut pemenuhan segera. Seseorang dengan kecerdasan emosi yang tinggi juga mampu untuk memahami perasaan orang lain dalam menangani hubungan.

\section{B. Beban Kerja}

Menurut Siswanto (2017:38) "beban kerja adalah sejumlah kegiatan yang harus diselesaikan oleh suatu unit sorganisasi atau pemegang jabatan secara sistematis dengan menggunakan teknis analisis jabatan, teknik analisis beban kerja, atau teknik manajemen lainnya dalam jangka waktu tertentu untuk mendapatkan informasi tentang efisiensi dan efektivitas kerja suatu unit organisasi."

Perhitungan beban kerja dapat dilihat dari 3 aspek yakni fisik, mental dan panggunaan waktu. Aspek fisik meliputi beban kerja berdasarkan kriteria-kriteria fisik manusia. Aspek mental merupakan perhitungan beban kerja dengan mempertimbangkan aspek 
mental (psikologis). Sedangkan aspek pemanfaatan waktu lebih mempertimbangkan pada aspek pengunaan waktu untuk bekerja.

\section{Kinerja Karyawan}

Kinerja (performance) adalah suatu gambaran tentang aktivitas-aktivitas pegawai dalam menetapkan selisih antara hasil akhir yang diharapkan dengan hasil aktual yang sesungguhnya. Kinerja dapat pula diartikan sebagai hasil atau tingkatan keberhasilan seseorang secara keseluruhan selama periode tertentu dalam melaksanakan tugas dibandingkan dengan standar hasil kerja, target atau kriteria yang telah ditentukan terlebih dahulu dan telah disepakati bersama. Kinerja tidak berdiri sendiri tapi berhubungan dengan kompensasi dan disiplin kerja.

Pengertian kinerja menurut Mangkunegara (2016:75) "istilah kinerja berasal dari kata job performance atau actual performance. Kinerja adalah hasil kerja secara kualitas dan kuantitas yang dicapai olehseorang pegawai dalam melaksanakan tugasnya sesuai dengan tanggung jawab yang diberikan kepadanya".

\section{Kerangka Berfikir}

Kerangka berpikir yang baik akan menjelaskan secara teoritis hubungan antara variabel yang akan diteliti. Menurut Sugiyono (2017:60) "kerangaka berfikir merupakan model konseptual tentang bagaimana teori berhubungan dengan berbagai faktor yang telah didefinisikan sebagai masalah yang penting". Sedangkan menurut Suriasumantri (2017:60) "kerangka pemikiran ini merupakan penjelasan sementara terhadap gejalagejala yang menjadi objek permasalahan". Salah satu hal yang dapat dilakukan untuk meningkatkan kinerja karyawan yaitu melalui penerapan kecerdasan emosional dan beban kerja yang sesuai dengan kemampuan para karyawan agar setiap tugas mereka dengan baik.

\section{METODE PENELITIAN}

\section{A. Jenis Penelitian}

Jenis penelitian ini adalah penelitian asosiatif, menurut Sugiyono (2017:44) yaitu penelitian yang bertujuan untuk mengetahui pengaruh atau hubungan antara dua variabel atau lebih. dengan demikian penelitian asosiatif ini dapat dibangun suatu teori yang berfungsi untuk menjelaskan, meramalkan dan mengontrol suatu gejala. Penelitian ini merupakan studi empiris yang bertujuan untuk menguji pengaruh kompensasi dan disiplin kerja terhadap kinerja karyawan

\section{B. Tempat dan Waktu Penelitian}

Waktu Penelitian ini dilaksanakan selama 7 (tujuh) bulan yang dimulai dari bulan Januari - Juli 2021. Adapun penelitian dilakukan secara bertahap disesuaikan dengan tingkat kebutuhan penulis, diawali dengan persiapan pendahuluan berupa penulisan skripsi judul penelitian, seminar proposal, penyempurnaan materi proposal, pembuatan instrumen penelitian, pengumpulan data primer dan skunder, pengolahan data yang telah didapat oleh penulis dan penyusunan pelaporan skripsi.

\section{Populasi}

Menurut Sugiyono (2017:215) berpendapat "populasi adalah jumlah wilayah generalisasi yang terdiri atas obyek dan karakteristik yang ditetapkan oleh peneliti dan kemudian ditarik kesimpulannya". Sedangkan menurut Arikunto (2015:173) menyampaikan bahwa "populasi adalah keseluruhan subjek penelitian". Dari pengertian di atas, disimpulkan populasi adalah keseluruhan karakteristik atau sifat subjek atau objek yang dapat ditarik sebagai sampel. Dalam penelitian populasinya adalah karyawan PT. Sony Indonesia yang berjumlah 160 karyawan.

\section{Sampel}

Menurut Sugiono (2017) sampel merupakan bagian dari jumlah dan 
karakteristik yang dimiliki oleh populasi tersebut. Bila populasi besar, dan peneliti tidak mungkin mempelajari semua yang ada pada populasi, misalnya karena keterbatasan dana, tenaga dan waktu, maka peneliti dapat menggunakan sampel yang diambil dari populasi itu. Dalam penelitian ini sampel yang diambil adalah 62 karyawan.

\section{E. Teknik Sampling}

Menurut Sugiyono (2017:81) “Tehnik sampling merupakan tehnik pengambilan sampel untuk digunakan dalam penelitian". Dalam penelitian ini menggunakan probability sampling. Menurut Sugiyono (2017:118) "Probability sampling adalah teknik pengambilan sampling yang memberikan peluang yang sama bagi setiap anggota populasi untuk dipilih menjadi anggota sampel".

$$
n=\frac{N}{1+N(e)^{2}}
$$

Keterangan :

$\mathrm{n}$ : Ukuran Sampel

$\mathrm{N}$ : Jumlah Populasi

e : Kesalahan dalam mengambil sampel yang ditetapkan sebesar 10\%

Dengan demikian sampel dalam penelitian ini adalah 160 karyawan. Jadi besarnya sampel yang digunakan adalah:

$$
\begin{aligned}
& \qquad n=\frac{N}{1+N(e)^{2}} \\
& n=\frac{160}{1+160(0,1)^{2}}=\frac{160}{2,6}=61,54 \\
& n=61,54 \text { dibulatkan menjadi } 62 \\
& \text { responden }
\end{aligned}
$$

\section{HASIL DAN PEMBAHASAN Hasil Penelitian}

Dalam penelitian ini yang menjadi responden adalah sampel karyawan PT. Sony Indonesia di Jakarta Pusat yaitu sebanyak 62 karyawan. Karakteristik responden meliputi jenis kelamin, usia, masa kerja dan pendidikan. Adapun karakteristik responden dapat disajikan dalam tabel dibawah ini:

Tabel 1. Data Responden Berdasarkan Jenis Kelamin

\begin{tabular}{|c|c|c|}
\hline Jenis Kelamin & Jumlah & Presentase \\
\hline Laki - Laki & 32 & $52 \%$ \\
\hline Perempuan & 30 & $48 \%$ \\
\hline Jumlah & 62 & $100 \%$ \\
\hline
\end{tabular}

Sumber: data olahan kuesioner, 2021

Tabel 2. Data Responden Berdasarkan Usia

\begin{tabular}{|c|c|c|}
\hline Usia & Jumlah & Presentase \\
\hline $20-35$ & 35 & $56,4 \%$ \\
\hline $36-45$ & 15 & $24,2 \%$ \\
\hline $46-65$ & 12 & $19,4 \%$ \\
\hline Jumlah & 62 & $100 \%$ \\
\hline
\end{tabular}

Sumber: data olahan kuesioner, 2021

Tabel 3. Data Responden Berdasarkan Pendidikan

\begin{tabular}{|c|c|c|}
\hline Pendidikan & Jumalah & Presentase \\
\hline SMA/SMK & 30 & $48,4 \%$ \\
\hline Diplomat/D3 & 9 & $14,5 \%$ \\
\hline Sarjana/S1/S2/S3 & 23 & $37,1 \%$ \\
\hline Jumlah & 62 & $100 \%$ \\
\hline
\end{tabular}

Sumber: data olahan kuesioner, 2021

Tabel 4. Data Responden Berdasarkan Lama Bekerja

\begin{tabular}{|c|c|c|}
\hline Lama Bekerja & Jumlah & Presentase \\
\hline 0-10 Tahun & 56 & $90,3 \%$ \\
\hline 11-20 Tahun & 6 & $9,7 \%$ \\
\hline 21-31 Tahun & 0 & $0 \%$ \\
\hline Jumlah & 62 & $100 \%$ \\
\hline
\end{tabular}

Sumber: data olahan kuesioner, 2021

\section{Uji Validitas}

Tabel 5. Pengujian Validitas Instrumen pernyataan Kecerdasan Emosional $\left(\mathrm{X}_{1}\right)$

\begin{tabular}{|l|c|c|c|}
\hline \multicolumn{1}{|c|}{ Pernyataan } & $\begin{array}{c}\mathbf{r} \\
\text { hitung }\end{array}$ & $\begin{array}{c}\mathbf{r} \\
\text { tabel }\end{array}$ & Keputusan \\
\hline $\begin{array}{l}\text { 1. Karyawan mengetahui kelemahan mereka dan mereka } \\
\text { mengembangkan kemampuan yang mereka miliki tanpa } \\
\text { menutupi kelemahan tersebut. }\end{array}$ & 0,513 & 0,250 & Valid \\
\hline $\begin{array}{l}\text { 2. Karyawan tetap bisa tenang bahkan ketika mereka marah atau } \\
\text { panik karena sesuatu hal. }\end{array}$ & 0,569 & 0,250 & Valid \\
\hline $\begin{array}{l}\text { 3. Karyawan selalu mempertimbangkan perasaan orang lain } \\
\text { ketika mereka menyelesaikan konflik ditempat kerja. }\end{array}$ & 0,524 & 0,250 & Valid \\
\hline 4. Karyawan kadang-kadang egois dalam memberikan pendapat. & 0,479 & 0,250 & Valid \\
\hline
\end{tabular}




\begin{tabular}{|l|c|c|c|}
\hline $\begin{array}{l}\text { 5. Saat sedang stres, karyawan mengalihkan perhatian dengan } \\
\text { melakukan hal-hal yang positif. }\end{array}$ & 0,607 & 0,250 & Valid \\
\hline $\begin{array}{l}\text { 6. Saat sedang mengalami kegagalan, karyawan tidak mudah } \\
\text { putus asa. }\end{array}$ & 0,522 & 0,250 & Valid \\
\hline $\begin{array}{l}\text { 7. Karyawan dapat merasakan apa yang sedang dirasakan oleh } \\
\text { orang lain. }\end{array}$ & 0,617 & 0,250 & Valid \\
\hline $\begin{array}{l}\text { 8. Karyawan selalu terbuka kepada orang lain mengenai kondisi } \\
\text { mereka. }\end{array}$ & 0,417 & 0,250 & Valid \\
\hline $\begin{array}{l}\text { 9. Karyawan mampu bekerjasama dengan karyawan lain ditempat } \\
\text { bekerja. }\end{array}$ & 0,557 & 0,250 & Valid \\
\hline 10. Karyawan dapat menjadi pendengar yang baik & 0,624 & 0,250 & Valid \\
\hline
\end{tabular}
Sumber : pengolahan data, 2021

Berdasarkan tabel di atas diketahui

bahwa semua butir pernyataan pada variabel Kecerdasan Emosional dinyatakan Valid, hal itu dibuktikan dengan nilai $r$ hitung $>r$ tabel, $(n-2)=$ $62-2=60$ yaitu 0,250 . Dengan demikian data layak diteruskan sebagai data penelitian.

Tabel 6. Pengujian Validitas Instrumen pernyataan Beban Kerja $\left(\mathrm{X}_{2}\right)$

\begin{tabular}{|l|c|c|c|}
\hline \multicolumn{1}{|c|}{ Pernyataan } & r hitung & r tabel & Keputusan \\
\hline $\begin{array}{l}\text { 1. Karyawan dapat memanfaatkan waktu kerja } \\
\text { untuk melaksanakan tugas yang dijalani } \\
\text { dengan baik. }\end{array}$ & 0,673 & 0,250 & Valid \\
\hline $\begin{array}{l}\text { 2. Karyawan harus bekerja sangat cepat untuk } \\
\text { menyelesaikan pekerjaan mereka. }\end{array}$ & 0,561 & 0,250 & Valid \\
\hline $\begin{array}{l}\text { 3. Karyawan dapat meninggalkan kantor ketika } \\
\text { waktu kerja telah selesai. }\end{array}$ & 0,685 & 0,250 & Valid \\
\hline $\begin{array}{l}\text { 4. Karyawan mengerjakan pekerjaan yang sama } \\
\text { setiap harinya. }\end{array}$ & 0,575 & 0,250 & Valid \\
\hline $\begin{array}{l}\text { 5. Beban kerja karyawan sehari-hari sudah } \\
\text { sesuai dengan standar pekerjaan karyawan. }\end{array}$ & 0,756 & 0,250 & Valid \\
\hline $\begin{array}{l}\text { 6. Pada saat tertentu karyawan menjadi sangat } \\
\text { sibuk dengan pekerjaan mereka. }\end{array}$ & 0,558 & 0,250 & Valid \\
\hline $\begin{array}{l}\text { 7. Karyawan dapat menikmati pekerjaan yang } \\
\text { dilakukan. }\end{array}$ & 0,491 & 0,250 & Valid \\
\hline $\begin{array}{l}\text { 8. Pada saat jam istirahat karyawan masih } \\
\text { mengerjakan pekerjaan mereka. }\end{array}$ & 0,442 & 0,250 & Valid \\
\hline 9. Target yang harus dicapai dalam pekerjaan \\
sudah jelas.
\end{tabular}
Sumber : pengolahan data, 2021

Berdasarkan tabel di atas diketahui bahwa semua butir pernyataan pada variabel Beban Kerja dinyatakan Valid, hal itu dibuktikan dengan nilai $r$ hitung $>\mathrm{r}$ tabel, $(\mathrm{n}-2)=62-2=60$ yaitu 0,250 . Dengan demikian data layak diteruskan sebagai data penelitian.

Tabel 7. Pengujian Validitas Instrumen pernyataan Kinerja Karyawan $(Y)$

\begin{tabular}{|l|c|c|c|}
\hline \multicolumn{1}{|c|}{ Pernyataan } & $\begin{array}{c}\mathbf{r} \\
\text { hitung }\end{array}$ & $\begin{array}{c}\mathbf{r} \\
\text { tabel }\end{array}$ & Keputusan \\
\hline 1. Kualitas kerja saya jauh lebih baik dari karyawan lain. & 0,525 & 0,250 & Valid \\
\hline $\begin{array}{l}\text { 2. Saya dapat memahami semua pekerjaan yang diberikan kepada } \\
\text { saya dengan baik. }\end{array}$ & 0,714 & 0,250 & Valid \\
\hline $\begin{array}{l}\text { 3. Saya memiliki kemampuan yang baik untuk melaksanakan } \\
\text { pekerjaan }\end{array}$ & 0,647 & 0,250 & Valid \\
\hline $\begin{array}{l}\text { 4. Saya dapat menyelesaikan seluruh pekerjaan yang telah } \\
\text { dibebankan kepada saya. }\end{array}$ & 0,638 & 0,250 & Valid \\
\hline $\begin{array}{l}\text { 5anyaknya pekerjaan yang saya terima sesuai dengan } \\
\text { kemampuan saya. }\end{array}$ & 0,545 & 0,250 & Valid \\
\hline
\end{tabular}




\begin{tabular}{|l|c|c|c|}
\hline 6. Saya berusaha lebih keras daripada yang seharusnya & 0,593 & 0,250 & Valid \\
\hline $\begin{array}{l}\text { 7. Saya memiliki ketepatan yang bagus dalam melaksanakan } \\
\text { pekerjaan }\end{array}$ & 0,706 & 0,250 & Valid \\
\hline $\begin{array}{l}\text { 8. Saya dapat menjaga hubungan baik antar rekan kerja dalam } \\
\text { melakukan pekerjaan. }\end{array}$ & 0,625 & 0,250 & Valid \\
\hline $\begin{array}{l}\text { 9. Saya dapat memanfaatkan semua sumber daya organisasi } \\
\text { untuk membantu saya dalam bekerja. }\end{array}$ & 0,603 & 0,250 & Valid \\
\hline $\begin{array}{l}\text { 10. Saya dapat menyesuaikan diri dengan lingkungan kerja } \\
\text { organisasi. }\end{array}$ & 0,684 & 0,250 & Valid \\
\hline 11.Saya dapat memanfaatkan semua fasilitas kerja yang diberikan. & 0,620 & 0,250 & Valid \\
\hline
\end{tabular}

Sumber : pengolahan data, 2021

Berdasarkan tabel di atas diketahui bahwa semua butir pernyataan pada variabel Kinerja Karyawan dinyatakan Valid, hal itu dibuktikan dengan nilai $r$ hitung > r tabel, $(n-2)=62-2=60$ yaitu 0,250 . Dengan demikian data layak diteruskan sebagai data penelitian.

\section{Uji Reliabilitas}

Tabel 8. Uji Reliabilitas Variabel Kecerdasan Emosional $\left(\mathrm{X}_{1}\right)$

Reliability Statistics

\begin{tabular}{|r|r|}
\hline \multicolumn{2}{|c|}{ Reliability Statistics } \\
\hline Cronbach's Alpha & N of Items \\
\hline .735 & 10 \\
\hline
\end{tabular}

Sumber: pengolahan data SPSS 26

Dari tabel diatas dapat dilihat bahwa variabel kecerdasan emosional dikatakan reliabel, karena $\mathrm{r}_{\text {hitung }}$ lebih besar dari pada 0,60 , yaitu $0,735>0,60$ dikatakan reliabel dengan ketentuan $\mathrm{N}=$ 10 taraf signifikan $10 \%$.
Tabel 9. Uji Reliabilitas Variabel Beban Kerja $\left(\mathrm{X}_{2}\right)$

\section{Realibility Statistics}

\begin{tabular}{|r|r|}
\hline \multicolumn{2}{|c|}{ Reliability Statistics } \\
\hline Cronbach's Alpha & N of Items \\
\hline .763 & 9 \\
\hline Sumber: pengolahan data SPSS 26
\end{tabular}

Dari tabel diatas dapat dilihat bahwa variabel beban kerja dikatakan reliabel, karena $r_{\text {hitung }}$ lebih besar dari pada 0,60 , yaitu $0,763>0,60$ dikatakan reliabel dengan ketentuan $\mathrm{N}=9$ taraf signifikan 5\%.

Tabel 10. Uji Reliabilitas Variabel Kinerja Karyawan $(\mathrm{Y})$

\section{Reliability statistics}

\begin{tabular}{|r|r|}
\hline \multicolumn{2}{|c|}{ Reliability Statistics } \\
\hline Cronbach's Alpha & N of Items \\
\hline .842 & 11 \\
\hline
\end{tabular}

Sumber:Pengolahan data SPPS 26

Dari tabel diatas dapat dilihat bahwa variabel kinerja karyawan dikatakan reliable, karena $r_{\text {hitung }}$ lebih besar dari pada 0,60, yaitu 0,842>0,60 dikatakan reliable dengan ketentuan $\mathrm{N}=$ 11 taraf signifikan 5\%.

\section{Uji Normalitas}

Tabel 11. Uji Normalitas

\begin{tabular}{|l|l|r|}
\hline \multicolumn{2}{|c|}{ One-Sample Kolmogorov-Smirnov Test } \\
\hline $\mathrm{N}$ & Unstandardized Residual \\
\hline \multirow{2}{|c|}{ Normal Parameters ${ }^{\mathrm{a}, \mathrm{b}}$} & Mean & 62 \\
\cline { 2 - 3 } & Std. Deviation & .0000000 \\
\hline \multirow{2}{*}{ Most Extreme Differences } & Absolute & 2.85364877 \\
\cline { 2 - 3 } & Positive & .096 \\
\cline { 2 - 3 } & Negative & .096 \\
\hline Test Statistic & -.058 \\
\hline Asymp. Sig. (2-tailed) & .096 \\
\hline a. Test distribution is Normal. \\
\hline \multicolumn{2}{|l|}{ b. Calculated from data. } \\
\hline \multicolumn{2}{|l|}{ c. Lilliefors Significance Correction. } \\
\hline \multicolumn{2}{|l|}{ d. This is a lower bound of the true significance. } \\
\hline
\end{tabular}

Sumber: Pengolahan data SPPS 26, 2021 
Dari tabel diatas dapat dikatakan bahwa nilai signifikan (2-tailed) sebesar 0,200 . Karena dikatakan signifikan apabila lebih dari $0,50(0,200>0,50)$ artinya data tersebut berdistribusi normal.

\section{Uji Heteroskedastisitas}

Tabel 12. Hasil Pengujian Heteroskesdastisitas Dengan Uji Glejser

\begin{tabular}{|c|c|c|c|c|c|}
\hline \multirow[b]{3}{*}{ Model } & \multicolumn{3}{|c|}{ Coefficients $^{a}$} & \multirow[b]{3}{*}{$t$} & \multirow[b]{3}{*}{ Sig. } \\
\hline & \multicolumn{2}{|c|}{ Unstandardized Coefficients } & \multirow{2}{*}{\begin{tabular}{|c|} 
Standardized Coefficients \\
Beta
\end{tabular}} & & \\
\hline & B & Std. Error & & & \\
\hline \begin{tabular}{|l|l|}
1 & (Constant) \\
\end{tabular} & 9.100 & 32.187 & & .283 & .778 \\
\hline Kecerdasan Emosional & .057 & .476 & .016 & .119 & .906 \\
\hline Beban Kerja & -.277 & .572 & -.063 & -.484 & .630 \\
\hline
\end{tabular}

Sumber : data diolah, 2021

Berdasarkan hasil pengujian pada tabel di atas, glejser test model pada variabel Kecerdasan Emosional (X1) diperoleh nilai probability signifikansi (Sig.) sebesar 0,906 dan Beban Kerja (X2) diperoleh nilai probability signifikansi (Sig.) sebesar 0,630 dimana keduanya nilai signifikansi (Sig.) > 0,05. Dengan demikian regression model pada data ini tidak terganggu heteroskesdastisitas, sehingga model regresi ini layak dipakai sebagai penelitian.

Kemudian pengujian bisa dilakukan dengan melihat grafik scatter plot antara nilai prediksi variabel terikat dan nilai residualnya, dengan ketentuan sebagai berikut :

\section{Uji Multikolinieritas}

Tabel 13. Uji Multikolinearitas

\begin{tabular}{|c|c|c|c|c|c|c|c|}
\hline \multicolumn{8}{|c|}{ Coefficients $^{a}$} \\
\hline \multirow[b]{2}{*}{ Model } & \multicolumn{2}{|c|}{$\begin{array}{c}\text { Unstandardized } \\
\text { Coefficients }\end{array}$} & \multirow{2}{*}{$\begin{array}{c}\text { Standardized } \\
\text { Coefficients }\end{array}$} & \multirow[b]{2}{*}{$\mathrm{t}$} & \multirow[b]{2}{*}{ Sig. } & \multicolumn{2}{|c|}{$\begin{array}{c}\text { Collinearity } \\
\text { Statistics }\end{array}$} \\
\hline & B & Std. Error & & & & Tolerance & VIF \\
\hline \begin{tabular}{|l|l}
1 & (Constant) \\
\end{tabular} & 8.941 & 7.291 & & 1.226 & .225 & & \\
\hline Kecerdasan Emosional & .124 & .108 & .115 & 1.152 & .254 & .992 & 1.008 \\
\hline Beban Kerja & .836 & .130 & .645 & 6.447 & .000 & .992 & 1.008 \\
\hline
\end{tabular}

a. Dependent Variable: KINERJA KARYAWAN

Sumber: hasil pengolahan SPSS 26, 2021

Berdasarkan hasil pengujian multikolinearitas pada tabel 4.13 diperoleh nilai tolerance variabel Kecerdasan Emosional sebesar 0,992 dan Beban Kerja sebesar 0,992 dimana kedua nilai tersebut lebih dari 0,10 dan nilai VIF variabel Kecerdasan Emosional sebesar a. Jika data menyebar tidak membentuk suatu pola maka tidak terjadi gangguan heteroskedastisitas.

b. Jika data membentuk pola tertentu maka telah terjadi gangguan heteroskesdastisitas.

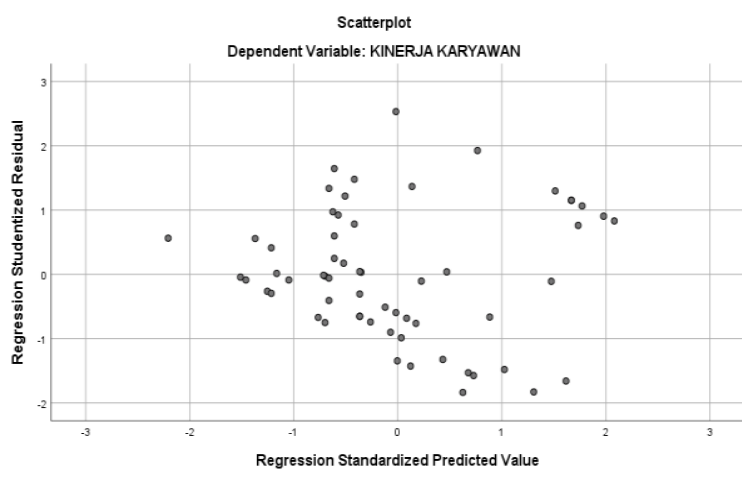

Gambar 1. Grafik Scatter Plot Hasil Uji Heteroskedastisitas
1,008 serta Beban Kerja sebesar 1,008 dimana berarti nilai tersebut kurang dari 10. Dengan demikian dapat disimpulkan bahwa tidak terjadi gejala Multikolinearitas diantara variabel bebas. 


\section{Regresi Linear Berganda}

Tabel 14. Hasil Pengolahan Regresi Variabel Kecerdasan Emosional $\left(\mathrm{X}_{1}\right)$

\begin{tabular}{|c|c|c|c|c|c|c|c|}
\hline \multicolumn{8}{|c|}{ Coefficients $^{a}$} \\
\hline \multirow[b]{2}{*}{ Model } & \multicolumn{2}{|c|}{$\begin{array}{c}\text { Unstandardized } \\
\text { Coefficients }\end{array}$} & \multirow{2}{*}{$\begin{array}{c}\text { Standardized } \\
\text { Coefficients }\end{array}$} & \multirow[b]{2}{*}{$t$} & \multirow[b]{2}{*}{ Sig. } & \multicolumn{2}{|c|}{$\begin{array}{c}\text { Collinearity } \\
\text { Statistics }\end{array}$} \\
\hline & B & Std. Error & & & & Tolerance & VIF \\
\hline 1 (Constant) & 8.941 & 7.291 & & 1.226 & .225 & & \\
\hline Kecerdasan Emosional & .124 & .108 & .115 & 1.152 & .254 & .992 & 1.008 \\
\hline Beban Kerja & .836 & .130 & .645 & 6.447 & .000 & .992 & 1.008 \\
\hline
\end{tabular}

Sumber: hasil pengolahan SPSS 26,2021

Berdasarkan hasil perhitungan uji regresi berganda yang terdapat pada tabel, dapat diketahui persamaan regresi yang terbentuk adalah :

\section{$\mathrm{Y}=8.941+0.124\left(\mathrm{X}_{1}\right)+0.836\left(\mathrm{X}_{1}\right)$}

Nilai konstant sebesar 8.941, artinya kinerja pegawai walaupun tanpa dipengaruhi oleh Kecerdasan Emosional dan Beban Kerja sudah mempunyai pengaruh sebesar 9.941 a) Pengaruh variabel Kecerdasan Emosional terhadap Kinerja Karyawan adalah positif. Artinya semakin baik kecerdasan emosional, maka kinerja karyawan akan meningkat sebesar 0,124.

b) Pengaruh variabel Beban Kerja terhadap Kinerja Karyawan adalah positif. Artinya semakin tinggi beban kerja maka kinerja karyawan akan meningkat sebesar 0,836 .

Tabel 15. Korelasi Nilai R Variabel $X_{1}$ dan $X_{2}$ terhadap Variabel $Y$

\begin{tabular}{|c|c|c|c|c|}
\hline & & $\begin{array}{c}\text { Kecerdasan } \\
\text { Emosional }\end{array}$ & $\begin{array}{l}\text { Beban } \\
\text { Kerja }\end{array}$ & $\begin{array}{c}\text { Kinerja } \\
\text { Karyawan }\end{array}$ \\
\hline Kecerdasan & Pearson Correlation & 1 & -.091 & .057 \\
\hline Emosional & Sig. (2-tailed) & & .482 & .662 \\
\hline & $\mathrm{N}$ & 62 & 62 & 62 \\
\hline Beban Kerja & Pearson Correlation & -.091 & 1 & $.634^{* *}$ \\
\hline & Sig. (2-tailed) & .482 & & .000 \\
\hline & $\mathrm{N}$ & 62 & 62 & 62 \\
\hline Kinerja Karyawan & Pearson Correlation & .057 & $.634^{* *}$ & 1 \\
\hline & Sig. (2-tailed) & .662 & .000 & \\
\hline & $\mathrm{N}$ & 62 & 62 & 62 \\
\hline
\end{tabular}

Sumber : hasil pengolahan SPSS,2020

Tabel 16. Interprestasi Koefisien Korelasi

\begin{tabular}{|c|c|}
\hline Interval Koefisien & Tingkat Hubungan \\
\hline $0,00-0,199$ & Sangat Lemah \\
\hline $0,20-0,399$ & Lemah \\
\hline $0,40-0,599$ & Cukup Kuat \\
\hline $0,60-0,799$ & Kuat \\
\hline $0,80-1,000$ & Sangat Kuat \\
\hline
\end{tabular}

\section{Koefesien Determinasi}

Tabel 17. Hasil Analisis Koefisien

Determinasi

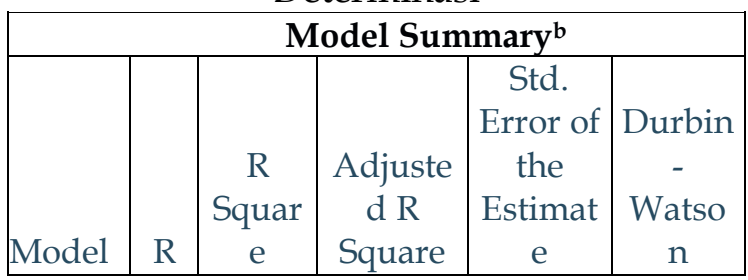

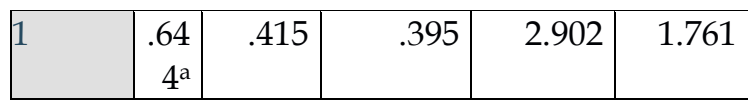

a. Predictors: (Constant), Beban Kerja, Kecerdasan Emosional

b. Dependent Variable: Kinerja Karyawan Sumber : hasil pengolahan SPSS,2021

Berdasarkan data tabel di atas, diperoleh nilai R-Square ( Koefisien determinasi) sebesar 0,415 dan dapat disimpulkan bahwa variabel Kecerdasan Emosional $\left(\mathrm{X}_{1}\right)$ dan Beban Kerja $\left(\mathrm{X}_{2}\right)$ berpengaruh terhadap variabel Kinerja Karyawan (Y) sebesar 41,5\% sedangkan sisanya dipengaruhi oleh faktor lain. 
8. Uji F (simultan)

Tabel 18. Hasil Uji Simultan (Uji F)m

Kecerdasan Emosional dan Beban Kerja

Terhadap Kinerja Pegawai

\begin{tabular}{|c|c|c|c|c|c|}
\hline \multicolumn{6}{|c|}{ ANOVA $^{a}$} \\
\hline Model & \begin{tabular}{|l|} 
Sum of \\
Squares
\end{tabular} & df & $\begin{array}{l}\text { Mean } \\
\text { Square }\end{array}$ & $\mathrm{F}$ & Sig. \\
\hline \begin{tabular}{|l|l}
11 & Regression
\end{tabular} & 352.629 & 2 & 176.314 & 20.942 & $.000^{\mathrm{b}}$ \\
\hline Residual & 496.742 & 59 & 8.419 & & \\
\hline Total & 849.371 & 61 & & & \\
\hline
\end{tabular}

a. Dependent Variable: Kinerja Karyawan

b. Predictors: (Constant), Beban Kerja, Kecerdasan Emosional

Sumber: hasil pengolahan SPSS,2020

Berdasarkan hasil pengujian pada tabel diatas, dapat diketahui nilai signifikansi untuk pengaruh Kecerdasan Emosional (X1) dan Beban Kerja (X2) terhadap Kinerja Karyawan (Y) sebesar $0,000<0,05$ dan nilai Fhitung adalah sebesar 20,942 > nilai Ftabel 3,15. Dengan demikian maka H03 ditolak dan $\mathrm{Ha} 3$ diterima, hal ini menunjukkan bahwa terdapat pengaruh yang signifikan secara simultan antara Kecerdasan Emosional (X1) dan Beban Kerja (X2) terhadap Kinerja Karyawan (Y) pada PT. Sony Indonesia di Jakarta Pusat.

\section{Pembahasan Penelitian}

Setelah diketahui hasil temuan dalam hal ini kemudian di analisis seberapa baik data tersebut mempresentasikan hasil penelitian yang diangkat, terutama kemapuan dalam menjelaskan seberapa baik Kecerdasan Emosional dan Beban Kerja terhadap Kinerja Karyawan. Selanjutnya akan dilakukan pembahasan hasil-hasil dalam penelitian ini sebagai berikut :

1. Pengaruh variabel Kecerdasan Emosional (X1) Secara Parsial Terhadap Kinerja Karyawan (Y)

Berdasarkan analisis hasil perhitungan SPSS versi 26, diperoleh nilai persamaan regresi linier berganda $Y$ $=8.941+0.124(\mathrm{X} 1)+0.836(\mathrm{X} 2)$, hasil uji $\mathrm{t}$ Variabel penelitian Kecerdasan Emosional sebagai variabel independen terhadap Kinerja Karyawan sebagai variabel dependen menunjukan hasil uji thitung 1,152 < ttabel 2,00100 dengan taraf signifikan 0,254 > 0,05 maka H01 diterima dan Ha1 ditolak artinya tidak terdapat pengaruh yang signifikan secara parsial antara Kecerdasan Emosional terhadap Kinerja Karyawan pada PT. Sony Indonesia di Jakarta Pusat.

2. Pengaruh Variabel Beban Kerja (X2) Secara Parsial Terhadap Kinerja Karyawan (Y)

Berdasarkan analisis hasil perhitungan SPSS versi 26, diperoleh nilai persamaan regresi linier berganda $Y$ $=8.941+0.124(X 1)+0.836(X 2)$, hasil uji t Variabel penelitian Beban Kerja sebagai variabel independen terhadap Kinerja Pegawai sebagai variabel dependen menunjukan hasil uji thitung 6,447 > ttabel 2,00100 dengan taraf signifikan $0,000<0,05$ maka Ha2 diterima dan $\mathrm{H} 02$ ditolak artinya terdapat pengaruh yang signifikan secara parsial antara Beban Kerja terhadap Kinerja Karyawan pada PT. Sony Indonesia di Jakarta Pusat.

3. Pengaruh Variabel Kecerdasan Emosional $\left(X_{1}\right)$ dan Beban Kerja $\left(X_{2}\right)$ Secara Simultan Terhadap Kinerja Karyawan (Y)

Berdasarkan dari hasil uji $F$ diketahui $F_{\text {hitung sebesar 20,942dengan }}$ tingkat sigifikan sebesar 0,000 $<0,05$. Kemudian degree of freedom (df) sebesar (k-1) atau derajat pembilangnya dan (nk) untuk derajat penyebutnya, dimana $n$ $=$ jumlah jumlah responden dan $\mathrm{k}=$ jumlah variabel yang diteliti, maka diperoleh $F_{\text {tabel }}$ sebesar 3,15. Sehingga nilai $\mathrm{F}_{\text {hitung }}$ lebih besar dari $\mathrm{F}_{\text {tabel }}(20,942>$ $3,15)$ maka $\mathrm{H}_{0}$ ditolak dan $\mathrm{H}_{\mathrm{a}}$ diterima. Dapat diartikan terdapat pengaruh positif dan signifikan antara kecerdasan emosional dan beban kerja terhadap kinerja karyawan secara simultan pada PT. Sony Indoonesia di Jakarta Pusat.

\section{Kesimpulan}

Berdasarkan hasil uraian bab-bab sebelumnya, dan dari hasil analisa serta pembahasan mengenai pengaruh kecerdasan emosional dan beban kerja 
terhadap kinerja karyawan PT. Sony Indonesia di Jakarta Pusat, sebagai berikut:

1. Secara parsial bahwa pengaruh Kecerdasan Emosional terhadap Kinerja Karyawan dapat diketahui dalam nilai thitung dari variabel kompensasi sebesar 1,152 dengan tingkat singnifikansi 0,05 dan derajat kebebasannya $\mathrm{df}=\mathrm{n}-\mathrm{k}-1$ (622-1) adalah sebesar 2,00100, jadi nilai thitung $(1,152<2,00100$ dengan nilai signifikansinya $0,254>0,05$. Maka dapat ditarik kesimpulan bahwa variabel kecerdasan emosional tidak berpengaruh signifikan terhadap kinerja karyawan.

2. Secara parsial bahwa pengaruh Beban Kerja terhadap Kinerja Karyawan. dapat diketahui nilai thitung dari variabel Beban Kerja sebesar 6,447 dengan tingkat signifikansi 0,05 dan derajat kebebasannya $\mathrm{df}=\mathrm{n}-\mathrm{k}-1$ (62-2-1) adalah sebesar 2,00100, jadi nilai thitung $(6,447>$ 2,00100) dan nilai signifikansinya $0,000<$ 0,05 . Maka dapat ditarik kesimpulan bahwa variabel disiplin kerja berpengaruh signifikan terhadap kinerja karyawan.

3. Hasil pengujian pengaruh simultan variabel bebas terhadap variabel terikatnya diperoleh nilia Fhitung $=$ 20,942 > nilai Ftabel $=3,15$ sehingga $\mathrm{H} 0$ ditolak dan Ha diterima. Sehingga dapat disimpulkan bahwa terdapat pengaruh yang signifikan antara Kecerdasan Emosional dan Beban Kerja Terhadap Kinerja Karyawan pada PT. Sony Indonesia.

\section{Saran}

Berdasarkan hasil pembahasan dan kesimpulan diatas dapat dikemukakan saran-saran sebagai berikut:

1. Dari hasil analisis jawaban kuesioner variabel kecerdasan emosional bahwa dalam indikator empati dan memelihara hubungan sosial perlu diperbaiki dimana indikator tersebut memiliki nilai terendah. Disarankan PT. Sony Indonesia di Jakarta Pusat dapat meningkatkan lagi rasa kesatuan di dalam perusahaan, sehingga karyawan mempunyai rasa bahwa perusahaan tempat mereka bekerja harus dibangun dan dijalankan bersama untuk mencapai tujuan perusahaan.

2. Dari hasil analisis jawaban kuesioner beban kerja bahwa dalam indikator beban waktu nilai tertinggi disarankan perusahaan senantiasa dapat bijak dalam memberikan tugas dan tanggung jawab kepada karyawan agar dapat meningkatkan kualitas karyawannya untuk bisa lebih baik lagi.

3. Bagi penelitian selanjutnya, agar dapat menambahkan lagi variabel-variabel lain dan tidak hanya sebatas pada tiga variabel ini saja, karena masih terdapat banyak kemungkinan variabel lain yang mempunyai pengaruh signifikan terhadap kinerja karyawan pada PT. Sony Indonesia.

\section{DAFTAR PUSTAKA}

Afandi, P. (2018). Manajemen Sumber Daya Manusia (Teori, Konsep dan Indikator). Riau: Zanafa Publishing.

Akimas, H. N. (2016). Pengaruh Kecerdasan Intelektual (IQ), Kecerdasan Emosional (EQ), Kecerdasan Spiritual (SQ) Terhadap Kinerja Pegawai Inspektorat Provinsi Kalimantan Selatan. Jurnal Wawasan Manajemen Vol.4 No.3.

Darmadi, H. (2013). Metode Penelitian Pendidikan dan Sosial . Bandung: Alfabeta.

Fahmi, I. (2013). Manajemen Kinerja, Teori dan Aplikasinya. Bandung: Alfabeta.

G, L. A. (2018). Pengaruh Kecerdasan Intelektual (IQ), Kecerdasan Emosional (EQ), Dan Kecerdasan Sosial (SQ) Terhadap Kinerja Karyawan Kantor Wilayah Bank Bri Manado. Jurnal Riset Ekonomi, Manajemen, Bisnis dan Akuntasi. Vol. 6 No. 4.

Hasibuan. (2017). Manajemen Sumber Daya Manusia . Jakarta: PT. Bumi Aksara.

Imanuel. (2018). Pengaruh Beban Kerja Dan Dukungan Organisasi Terhadap Kinerja Karyawan Pada Koperasi Kredit Pintu Air Cabang Maumere. 
Jurnal Projemen UNIPA Maumere. Vol. 5 No. 2.

Judge, R. \&. (2015). Perilaku Organisasi Edisi 16. Jakarta: Salemba Empat.

Kadek. (2016). Pengaruh Kecerdasan Intelektual, Kecerdasan Emosional, Kecerdasan Spiritual, Komitmen Organisasi Terhadap Kinerja Auditor. E-Jurnal Akuntasi Universitas udayana Vol. 17. No. 2, 1168-1195.

Kiki. (2021). Pengaruh Kecerdasan Emosional, Disiplin Kerja Dan Kepercayaan Diri Terhadap Kinerja Karyawan Pada UD Toko. Jurnal EMAS Vol. 2 No. 2.

Mangkunegara, P. (2014). Manajemen Sumber Daya Manusia. Bandung : PT. Remaja Rosdakarya.

Ningrum. (2019). Pengaruh Kecerdasan Emosional Dan Kompensasi Terhadap Kinerja Karyawan (Studi Kasus Pada PT. Sumber Graha
Sejahtera). Jurnal Manajemen Vol. 5 No. 1, 5-10.

Rizal. (2019). Pengaruh Lingkungan Kerja, Kepuasan Kerja Dan Beban Kerja Terhadap Kinerja Karyawan. Jurnal Magister Manajemen Vol. 2 No. 2.

Simamora. (2014). Manajemen Sumber Daya Manusia. Yogyakarta: Sekolah Tinggi Ilmu Ekonomi YKPN.

Sugiharjo, R. J. (2018). Pengaruh Beban Kerja Dan Motivasi Kerja Terhadap Kinerja Karyawan BPJS Keternagakerjaan Cabang Salemba. Jurnal Ilmiah Manajemen Bisnis Vol. 4 No. 1.

Sugiyono. (2017). Metode Penelitian Kuantitatif, Kualitatif dan R\&D . Bandung: Alfabeta.

Sulastri. (2020). Pengaruh Stres Kerja, Dan Beban Kerja Terhadap Kinerja Karyawan. Journal of Management and Bussines (JOMB). Vol. 2 No. 1. 